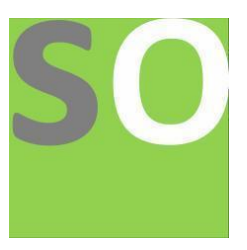

Article title: Engineering Plastics: Market Analysis and Recycling Methods

Authors: Fatih Selim Yildizhan[1]

Affiliations: LL.M., University of Fribourg, Fribourg, Switzerland[1]

Orcid ids: 0000-0002-5552-4763[1]

Contact e-mail: fsyildizhan@gmail.com

License information: This work has been published open access under Creative Commons Attribution License $\mathrm{http}: / / c r e a t i v e c o m m o n s . o r g / l i c e n s e s / b y / 4.0 /$, which permits unrestricted use, distribution, and reproduction in any medium, provided the original work is properly cited. Conditions, terms of use and publishing policy can be found at https://www.scienceopen.com/.

Preprint statement: This article is a preprint and has not been peer-reviewed, under consideration and submitted to ScienceOpen Preprints for open peer review.

DOI: 10.14293/S2199-1006.1.SOR-.PPOYUPU.v1

Preprint first posted online: 30 January 2021

Keywords: engineering plastics, plastics market, recycling 


\section{ENGINEERING PLASTICS, MARKET ANALYSIS AND RECYCLING METHODS}

January 2021

Fatih Selim Yildizhan

LL.M. University of Fribourg, Switzerland

Commodity Trading

\&

International Business Law 


\section{LIST OF ABBREVIATIONS}

\begin{tabular}{|c|c|}
\hline CAGR & Compound annual growth rate \\
\hline WEEE & Waste Electrical \& Electronic Equipment \\
\hline ABS & Acrylonitrile-Butadiene-Styrene \\
\hline LCP & Liquid Crystal Polymers \\
\hline PA & Polyamide \\
\hline PBT & Polybutylene Terephthalate \\
\hline PC & Polycarbonate \\
\hline PE & Polyethylene \\
\hline PEEK & Polyaryletheretherketone \\
\hline $\mathrm{PI}$ & Polyimide \\
\hline PMMA & Polymethyl methacrylate \\
\hline POM & Polyoxymethylene \\
\hline PP & Polypropylene \\
\hline PPA & Polyphthalamide \\
\hline PPS & Polyphenylene sulfide \\
\hline PS & Polystyrene \\
\hline PSU/P/PPSU & Polyarylsulfone \\
\hline PVC & Polyvinyl chloride \\
\hline PVDF & Polyvinylidene fluoride \\
\hline TPE-E & Thermoplastic polyester elastomer \\
\hline UHMWPE & Ultra-high-molecular-weight polyethylene, sometimes shortened to UH \\
\hline HIPS & High impact polystyrene \\
\hline
\end{tabular}




\section{A. What Are Engineering Plastics?}

Engineering plastics is a category of plastics, mostly used for high-performance applications such as heat resistance, chemical resistance, impact, flame retardance or mechanical strength.

Engineering plastics are more effective than commodity plastics and are ideal for applications that need engineering to design components used for their intended use ${ }^{1}$.

Contrary to engineering plastics, commodity plastics are relatively cheap and have weaker mechanical properties. These materials are being produced as high volume plastics for applications such as packaging, and general household goods, in which superior material characteristics are not required ${ }^{2}$.

\begin{tabular}{|l|ll|}
\hline Common Engineering Thermoplastics in Plastics \\
Industry & & \multicolumn{1}{c|}{ Commodity Plastics } \\
\hline - ABS (Acrylonitrile-Butadiene-Styrene) & - Polyethylene (PE) \\
- LCP (Liquid Crystal Polymers) & - Polypropylene (PP) \\
- PBT (Polybutylene Terephthalate) & - Polystyrene (PS) \\
- PEEK (Polyaryletheretherketone) & - Polyvinyl chloride (PVC) \\
- PMMA (Polymethyl methacrylate) & & \\
- PA (Polyamide) & \\
- PSU/P/PPSU (Polyarylsulfone) & \\
- PI (Polycarbonate) & \\
- POM (Polyoxymethylene) & \\
- PPA (Polyphthalamide) & \\
- PPS (Polyphenylene sulfide) & \\
- PVDF (Polyvinylidene fluoride) & \\
- TPE-E (Thermoplastic polyester & \\
elastomer) & \\
& \\
& UHMWPE (Ultra-high-molecular-weight \\
polyethylene, sometimes shortened to &
\end{tabular}

Besides commodity plastics and engineering plastics, there are also high-performance plastics which differ from standard plastics and engineering plastics primarily by their temperature stability, chemical resistance and mechanical properties. These are plastics that meet higher requirements than standard or engineering plastics. They are more expensive and usually used in lesser amounts ${ }^{3}$.

\footnotetext{
${ }^{1}$ (Foundation, 2020)

2 (Europe, 2015)

${ }^{3}$ (Kemmish, 2011)
} 


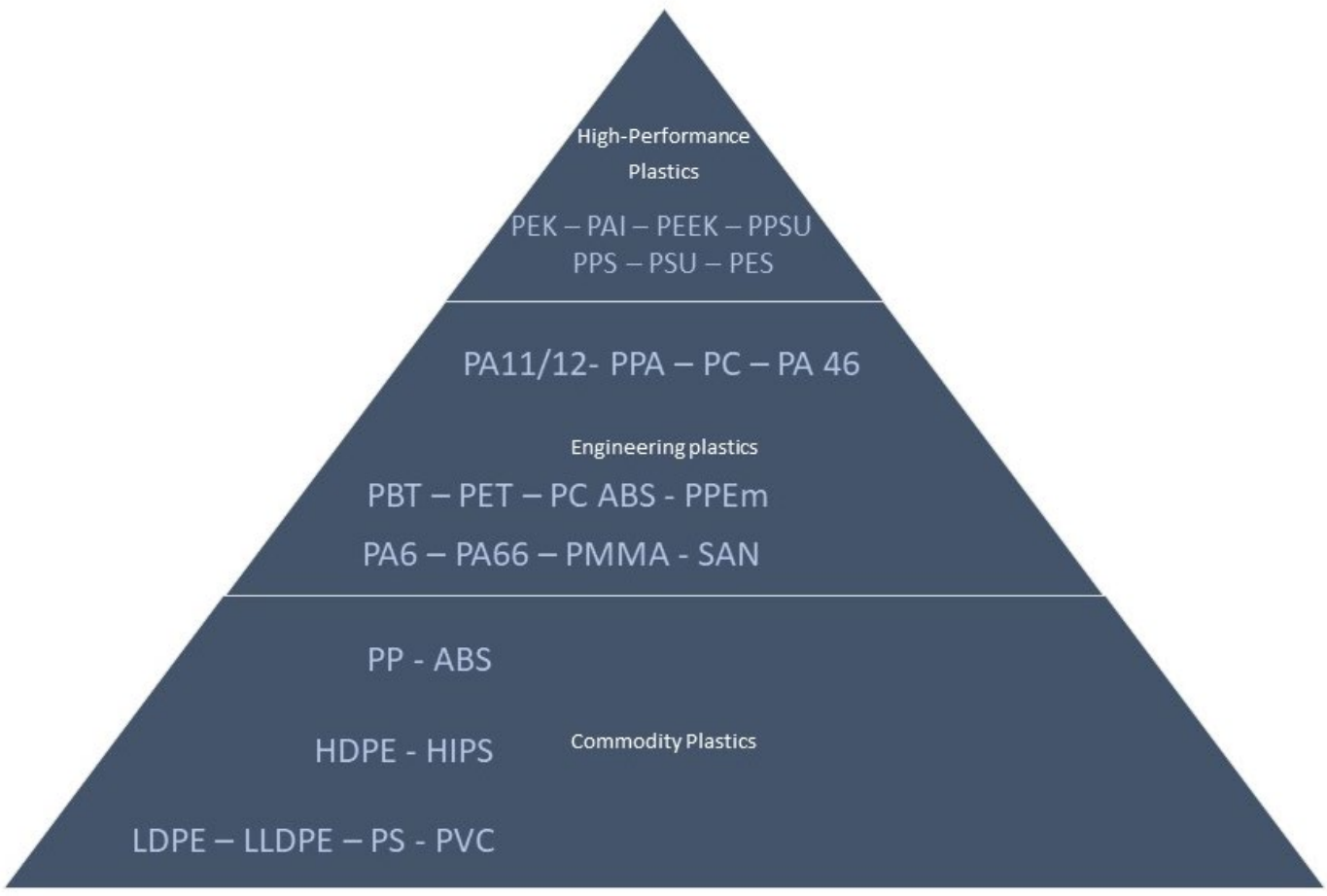

Figure 1.1. Plastics According to Their Performances

In the chart above, price and performance increases through higher levels while production volume is decreasing.

\section{B. Global Market Analysis}

According to market analysis based on the products listed as;

- Fluoropolymers

- Polycarbonate (PC)

- Polyethylene Terephthalate (PET)

- Polybutylene Terephthalate (PBT)

- Polyacetal/ Polyoxymethylene

- Polymethyl Methacrylate (PMMA)

- Polyphenylene Oxide

- Polyphenylene Sulfide (PPS)

- Styrene Copolymers (ABS and SAN)

- Liquid Crystal Polymers (LCP)

- Polyether Ether Ketone (PEEK)

- Polyimides (PI)

- Polyamides 
the largest market for engineering plastics is Asia Pacific regionChina is the world 's largest engineering plastics manufacturer and user with a share of around $35 \%$ of the overall market ${ }^{4}$. In 2015 , the German plastics engineering industry represented almost $32 \%$ of the European market.

As main growth strategies, major players in the plastics engineering sector have embraced expansion and product development. Important players in the industry are;

- BASF SE (Germany)

- LG Chem (South Korea)

- Sabic Innovative Plastics (Saudi Arabia)

- Solvay SA (Belgium)

- Evonik Industries AG (Germany)

- Arkema SA (France)

- E. I. du Pont de Nemours and Company (U.S.)

- Royal DSM NV (Netherlands)

- Lanxess AG (Germany)

- Bayer AG (Germany)

By 2022 , it is estimated that the Engineering Plastics Market will hit $\$ 102$ billion from $\$ 67$ billion In 2015. The CAGR is expected to show more than 5\% for in the period 2020-2025.

The most widely used engineering plastic in the world is Polyethylen Terephthalate (PET). However, the highest CAGR for the forecast period will be predicted by Polyether Ether Ketone (PEEK).

In the plastics packaging industry, PET and polyolefins are the most commonly used materials. The recyclability, strength and flexibility drive demand for PET as packaging material. The products include mainly containers to be taken, froze food, carbonated beverages and juices, ketchup, water bottles. They are also used for jars, deli containers and microwave food trays in the food industry.

\section{Recycling of Engineering Plastics}

Plastic recycling involves the recuperation and reprocessing of waste material into usable items from scrap or used plastics. Recycling is a part of the global movement to eliminate solid waste plastics, as most plastics are non-biodegradable. However in mechanical recycling, in melting process, different types of plastics appear to be separated, and fall in certain layers this causes structural weakness in recycled materials, which makes them suitable for limited applications.

Commodity plastics such as; LDPE, HDPE and PP have been approved by recycling programs. Recycled LDPE is processed as waste bins, tables, mobilizers, floors, and wrap bubbles. The recycled HDPE can be used in plums, plastic wood, picnic tables, and bottles. And finally, recycled PP can be used as heavy-duty items like pallets, ice scrapers, rakes, and battery cables.

Mechanical plastics recycling means processing plastic waste into recycled products without altering the chemical composition of the material vastly. All thermoplastics can, in theory, be

\footnotetext{
${ }^{4}$ (Intelligence, 2019)
} 
recycled mechanically with a low to no decline inefficiency. It is now nearly the only method of recycling in Europe, with a rate of over $99 \%$.

Like commodity plastics, engineering plastics such as polycarbonate, acrylonitrile-butadienestyrene, polycarbonate/acrylonitrile-butadiene-styrene and acrylonitrile-butadiene-styrene/high impact polystrene material was also subject of material recycling through a melt blending process ${ }^{5}$.

During PC recycling, the durability of mixed plastics can be increased with addition of $\% 10$ virgin polycarbonate and other modifiers such as ethylene, acrylic ester or glycidyl methacrylate. The improved propensities of blended plastics show improved solubility with suitable high-end application.

The most commonly used plastics materials in WEEE are acrylonitrile butadiene-styrene (ABS), polycarbonate (PC) and high impact polystyrene (HIPS), along with various other plastics like polypropylene (PP), poly(phenylene oxide) (PPO), polyvinyl chloride (PVC), etc. The electrical and electronics industry is a leading user of these plastics, generating $33 \%$ of waste of engineering plastics.

Accordingly, the Waste Electrical \& Electronic Equipments (WEEE) are very good sources for recycling of engineering materials. However, the most important thing is to make a correct identification of the wastes in the sorting process. The identification of plastics is generally very difficult owing to the following problems associated with WEEE.

- There are wide selection of essential polymers for use.

- There are broad variety of additives which can be used to alter basic polymer properties.

- There are broad range of polymer blends or compounds that can be developed to achieve the required properties.

In order to make an effective identification of engineering plastics, one should consider their melting behaviour, Colour of flame/ kind of smoke and finally Odour/smell of the material. For example; HIPS Melts and bubbles around the edge, spurting, burns readily while ABS becomes soft but not fluid. PC melts but chars, bubbles develop, self-extinguishing.

Density and bending behaviour of the materials can also be important for identification; HIPS has a density of 1.07 and it cracks but retains bend, PC has 1.2 density and tough to bend while ABS has 1.05 density and bend tends to remain.

According to test over WEEE materials recycled with melt blending techniques by using segregated plastics from TV housing ( $A B S$ ), monitor bottom stand ( $A B S / P C)$, monitor back cover (PC/ABS), keyboard bottom plate (ABS/HIPS), television housing (ABS), central processing unit (CPU) casing (ABS), speaker box outer cover (ABS/ HIPS), liquid crystal display (LCD) monitor bottom stand $(P C), L C D$ monitor covers (PC), mouse cover (PC) and telephone casing (ABS), the observers made a conclusion that recycled plastics from WEEE can be used for high end application, with low cost and reasonable price ${ }^{6}$.

To conclude, it is possible to melt blend different type of engineering plastics together to obtain effective results since it is relatively more difficult to obtain scrap materials for engineering plastics compared to commodity plastics.

\footnotetext{
${ }^{5}$ (Ramesh V, 2 April 2014)

${ }^{6}$ (Ramesh V, 2 April 2014)
} 


\section{References}

Europe, P. (2015). Plastics - the Facts 2014/2015 - An analysis of European plastics; production, demand and waste data. Wemmel - Belgium: PlasticsEurope.

Foundation, P. -T. (2020, 11 10). Engineering Plastics. Retrieved from PAGEV: https://pagev.org/engineering-plastics

Intelligence, M. (2019). ENGINEERING PLASTICS MARKET - GROWTH, TRENDS, AND FORECAST (2020 2025). Retrieved from Mordor Intelligence: https://www.mordorintelligence.com/industryreports/engineering-plastics-market

Kemmish, D. J. (2011). Practical Guide to High Performance Engineering Plastics. Shawbury, Shropshire: iSmithers.

Ramesh V, M. B. (2 April 2014). Recycling of engineering plastics from waste electrical and electronic equipments: Influence of virgin polycarbonate and impact modifier on the final performance of blends. Waste Management \& Research, 379-388. 